\title{
BIOLOGICAL CONTAMINATION: A SERIOUS CONSTRAINT IN LARGE SCALE MICROALGAE BIOMASS PRODUCTION
}

\section{Bidhu Bhusan Makut ${ }^{\text {a }}$, Saubhagya Manjari Samantaray ${ }^{\text {b }}{ }^{*}$}

\author{
aAlgaline Pvt. Ltd., Bhubaneswar-751020, Odisha, India \\ ${ }^{b}$ Department of Microbiology, College of basic science and humanities, Odisha University of \\ Agriculture and Technology, Bhubaneswar-751003, Odisha, India
}

*Corresponding author at: Saubhagya Manjari Samantaray, Department of Microbiology, College of basic science and humanities, Odisha University of Agriculture and Technology, Bhubaneswar-751003, Odisha, India

Email address: saubhagyasamantaray@yahoo.com

\begin{abstract}
Microalgae biomass is a budding raw material for the origination of food, fuel, and other value-added products. However, bulk production of microalgal biomass at commercial level is a herculean task for the current microalgal mass production technologies due to the undesirable contaminations by biological pollutants. These contaminants hamstring the production of microalgae biomass by debilitating the growth of cultures, crumble the quality of biomass and sometimes may crash the whole culture. The best utilization of the microalgae biomass at industrial level could be attained by avoiding various possible biological contaminations in mass cultivation system, understanding the contamination mechanisms, and the complex interactions of algae with other microorganisms. This review explores the various types of biological pollutants, their possible mode of infection along with mechanisms, different controlling methods to maintain desired microalgae culture.
\end{abstract}

Key words: Biological contaminants, grazers, microalgae, open cultivation, biopesticides

\section{Introduction}


Since the last few decades microalgae are enormously exploited as potential raw materials for food, fuel, and other value-added products. Many microalgae species have a huge range of industrial applications as they're capable of generating one-of-a-kind varieties of antioxidant, carotenoid, enzyme polymer, excessive-value bioactive compounds and also engaged within the synthesis of antimicrobial, and anticancer drugs [1]. In order to realize the potential utility of microalgae at industrial level, bulk volume of microalgal biomass should be cultivated in large scale at low cost. At present, most large-scale farming methods to generate a large amount of biomass from microalgae for biofuel and bioproduct production rely on raceway ponds and photobioreactors. Although there are a growing number of innovative and state-of-art engineered photobioreactors have been designed to produce microalgae biomass on a large scale, open raceway ponds drag the attention of the researchers to cultivate microalgae as they are less expensive to construct, free availability of solar energy and ease operation. However, there are some constraints during the operation of open raceway pond; i.e., it needs more energy for mixing of cultures, the water level should be kept below $15 \mathrm{~cm}$ in order to allow the sun light to penetrate, and the contamination caused by various pests (contaminants) particularly microzooplankton such as protozoa, rotifers, copepods and Cladocera [2]. These contaminants may hamper the production of microalgae biomass by impairing the growth of cultures, deteriorating the quality of biomass and sometimes may crash the whole culture. Therefore, biological contamination significantly barricades the development of microalgae industry at commercial level. In order to control the infection of biological pollutants, early detection and monitoring methods have been developed. Though there are several infection control methods such as physical, chemical, biological, and environmental methods adopted for the eradication of biological pollutants, none of the above conventional methods are successfully implemented due to certain short comings. This review outlines various types of invading biological pollutants with their routes of infection, detection and monitoring 
techniques, mechanisms of contamination, and necessary steps for controlling their contamination in large-scale microalgae cultivation.

\section{Different types of biological contaminants and their infection patterns}

Algae are the most promising candidate to keep the planet green by sharing nearly $50 \%$ of the total global photosynthetic activity. It has been observed that grazing by biological pests such as ciliates, amoeba, rotifers and other zooplankton affects the productivity and sustainability as well as the commercial viability of a collective culture of microalgae [3]. These biological contaminants are broadly categorised into two groups according to their nature of contamination; such as (1) Microalgae cell growth destroying contaminants and, (2) Microalgae cell growth inhibiting contaminants by consuming the secreted cellular products. Thus, early detection of biological contaminants is an imperative step during the large-scale microalgae and cyanobacteria cultivation in outdoor conditions. Staining and microscopy is one of the traditional morphological observation methods that can be used in early and routine detection methods [4]. Gerphagnon et al. [5] devised a modified staining approach for the detection of chitinous fluorochrome and nucleic acid stain in combination with epifluorescence microscopy and characterization of chytrid prolificacy in Anabaena macrospora, a cyanobacterium [4]. However, in large-scale industrial applications, automated detection systems would be perfect for the identification of biological pollutants at the beginning stage. FlowCAM (flow cytometry and microscopy) is an automated detection system, which was designed to characterize marine microplankton in the of 20-200 $\mu \mathrm{M}$ size range [6]. A modified FlowCAM system was developed by Havlik et al. [7] in order to monitor Chlorella vulgaris cultivation on-line for over 20 days through an in-situ microscope in order to obtain cell number, size, and morphology data. Modern molecular based methods, such as new-generation sequencing and quantitative PCR technologies, have recently been explored as highly sensitive and informative methods for identifying and characterizing biological contaminants [8]. There 
are a variety of biological contaminants compete for available resources with target microalgal species and co-exist with them. In Figure 1, we summarize the major groups of biological contaminants typically found in microalgal culture.

\begin{tabular}{|c|c|c|c|c|c|}
\hline Grazers & Fungi & Bacteria & Virus & Protozoans & Other microbes \\
\hline $\begin{array}{l}\text { Zooplankton } \\
\text { (rotifers, } \\
\text { ciliates, } \\
\text { copepods, } \\
\text { cladocera) }\end{array}$ & $\begin{array}{l}\text { Chytridiomycetes } \\
\text { species }\end{array}$ & $\begin{array}{c}\text { Alteromonassp., } \\
\text { Flavobacterium } \\
\text { sp., Cytophaga } \\
\text { sp., Myxobacter } \\
\text { sp., Bacillus sp., } \\
\text { and Pseudomonas } \\
\text { sp. }\end{array}$ & $\begin{array}{l}\text { LPP virus and } \\
\mathrm{CCV} \text { virus }\end{array}$ & $\begin{array}{l}\text { Amoeba, } \\
\text { flagellates, } \\
\text { and ciliates }\end{array}$ & $\begin{array}{l}\text { Other harmful } \\
\text { microalgae }\end{array}$ \\
\hline
\end{tabular}

Figure 1. Different biological contaminants present in microalgal cultures

Grazers: There are a number of contaminants known as grazers which consume a variety of microbes, including microalgae and have a profound impact on their communities. A majority of its component organisms are zooplanktons, protozoans, and other small organisms that consume microalgae very rapidly. Zooplankton have very fast growth rate with high ingestion rates and grazing capacity and are divided into picoplankton, nanoplankton, microplankton, mesoplankton, macroplankton and megaplankton according to their size [9]. In microalgal ponds, zooplankton are bigger than microalgae, including Ciliates, Rotifers, Copepods and Cladocera [9]. Their rapid chomping of algae reduces the microalgal biomass yield considerably. The most widely distributed freshwater zooplanktons are: Rotifers: Small zooplankton with a size less than 200 micrometres and a cell density of 1000 to 500,000 cells per litre. Rotifers are omnivorous in nature and mostly filter feeders grazing small microalgae. In contrast, some rotifer species such as Brachionus calyciflorus feed on elongated microalgae Ankistrodesmus sp., while others such as Cephalodella sp. graze on colonial microalgae Dictyosphaerium sp. [10]. 
Cladocera: The Cladocerans are small crustaceans which have a length of 0.2 to $5.0 \mathrm{~mm}$ and graze on a larger variety of microalgae compared to Rotifers. Daphnia and Moina are common cladocera species found in hypereutrophic environments. The rapid decline in algal concentration is due to the grazing activity of Daphnia and Moina.

Ostracoda: These are small crustaceans having $0.3-5.0 \mathrm{~mm}$ in length. Ostracods are omnivorous grazers which feed on organic remnants, bacteria, protozoa, dead plant and animal material, and algae. Aspects of the food web played by ostracoda are important in different aquatic ecologies [11, 12].

Copepoda: Small crustaceans of approximately 1 to $5 \mathrm{~mm}$ length, divided into (i) Calanoida, (ii) Cyclopoida, and (iii) Harpacticoida. Copepods primarily feed on algae, ciliates, small rotifers and bacteria [10]. It was reported by Li et al. [13] that incubation of ciliates within mass cultures of Dunaliella salina, reduced their cell density from $2.7 \times 10^{4}$ cells / $\mathrm{mL}$ to $1.2 \times 10^{4}$ cells / $\mathrm{mL}$ after two days. A rotifer, Brachionus plicatilis, consumes 12,000 cells of algae within a few hours, according to Park et al. [14].

Fungi: These are saprophytic eukaryotic microbes which can use microalgae nutritional conditions to grow. Microalgae secret dissolved organic carbon into the culture medium which allows the growth of fungi. Many fungi infest microalgae cultures, some of which cannot be identified completely, making it difficult to control the cultivation process [8]. Zoosporic fungi Chytridiomycetes species (e.g., Paraphysoderma sedebokerensis) is a pathogenic class of fungi present abundantly in freshwater cultures of Scenedesmus and Haematococcus; which can cause the reduction of $90 \%$ microalgae population [15]. These classes of fungi are very hostspecific those attack certain groups, species or strains of microalgae. In open pond systems, Phlyctidium scenedesmi kills Scenedesmus and damages its biomass production [16]. With the help of microbiome analysis and chitin staining, Carney et al. [8] observed great loss of biomass 
productivity while several chytrids co-occurred with green algae belong to family Scenedesmaceae, growing in Offshore Membrane Enclosures for Growing Algae (OMEGA) system. Karpov et al. [17] detailed that aphilids, which is a chytrid's sibling taxon nourish on microalgae. Letcher et al. [18] also reported that Amoeboaphelidium protococcarum, a novel aphilid infect and decrease the biomass content of Scenedesmus dimorphus culture growing in open ponds. Labyrinthulids and oomycetes are also associated with biomass loss of green algae.

Bacteria: Bacteria are the foremost noteworthy natural contaminants and contain a gigantic assortment of genera. Several groups of bacteria cause biological contamination in the microalgae culture. Bacteria can not only increase the defencelessness of the microalgae culture to allow the growth of other pathogens, but also reduce the dietary quality of the microalgae biomass. Microalgae growth is slowed by phytoplankton-lytic bacteria by (i) fighting for nutritional availability, (ii) secreting algicidal, a substance that can destroy both harmful and cultured algae (indirect attack), and (iii) causing algal cells to lyse as a result of direct contact [19]. The bacterial strains mainly Alteromonas sp., Flavobacterium sp., Cytophaga sp., Myxobacter sp., Bacillus sp., and Pseudomonas sp. lysis the microalgae cells by indirect attack or by secreting metabolites, 2,3-indolinedione, argimicin A, $\beta$ Cyanoalanine and proteins [9]. According to current research, phytoplankton-lytic bacteria kill microalgae by breaking the double helix structure of their DNA [20]. Furthermore, phytoplankton-lytic bacteria inhibit microalgal growth by rupturing the microalgal cell wall and causing intracellular material leakage [21].

Viruses: They are abundant in the aquatic environment, where they coexist with microalgae and cyanobacteria. Viral infection is also a significant biological contamination which reduces microalgal population within a few days as well as induce morphological structure changes in microalgal cells, their variety and sequences [17]. The rapid reduction in cell number of microalgae is due to the quick replication round and high specificity of virus. Generally, the 
infection mechanism of virus adopts the following steps: (1) They bind to the cell wall of the algal cell and lyse it, (2) insert their proteins and genetic material into the algal cellular machinery, (3) then they replicate themselves using host's transcription machinery [22]. LPP virus was first reported to infect the cyanobacterium [23]. CCV virus was first identified by Gibbs et al. [24] that infect the alga Chara coralline more specifically. Nagasaki et al. [25] devised a one-step growth experiment to assess $\mathrm{HaVo1}$ virus algicidal activity, which resulted in a reduction in host cell density from $1.27 \times 10^{5}$ to $10^{1}$ cells $/ \mathrm{ml}$, while HaVol cell density was enhanced from $2.58 \times 10^{5}$ to $9.8 \times 10^{7} \mathrm{LCU} / \mathrm{ml}$.

Protozoans: Protozoans are eukaryotic microorganisms that feed on microalgae cultures and include amoeba, flagellates, and ciliates [26]. They are the chief source of biological contamination in mass culture system which is very difficult to control. In unicellular, colonial, or filamentous algae or cyanobacteria, ciliates and amoebas are linked to lower cell densities. Generally, amoeba crawl in the bottom of the culture pond to consume food via phagocytic mechanism in its trophozoite stage. In some situations, vampyrellid amoeba puncture the prey’s cell membrane to consume its cytosolic material [27]. Typically, these protozoa have a negative impact on Chlorella and Spirulina bulk culture. Other microalgae species, cyanobacteria and photosynthetic microorganism: The cross contamination by other microalgae species, some of the cyanobacteria and photosynthetic microorganism is more harmful to the desired axenic microalgal culture. These contaminants have bad impact on quality of production. The growth of undesired photosynthetic species can overcome the growth of desired algal strain and compete for the available nutrient source [9]. The implications of this issue would be raised in terms of harvest biomass quality management. Furthermore, the toxin produced by the undesirable species poses a health risk to microalgae. As a result, both animals and people may be poisoned by the tainted algal biomass. Direct cell-to-cell contact, competition for available 
nutrients, and allelopathy are three contamination mechanisms that exist between distinct microalgae. (Figure 2).

\section{Direct cell to cell contact}

When the density of microalgae cells reaches a particular point, space competition occurs, resulting in mutual contact. In such a high cell density culture, the dominant microalgal species would be found abundantly than other. When Akashiwo sanguinea was mixed with Cochlodinium polykrikoides, Yasuhiro et al [28] noticed a conformation change and growth inhibition, which they attributed to cell-to-cell contact between the two algae species.

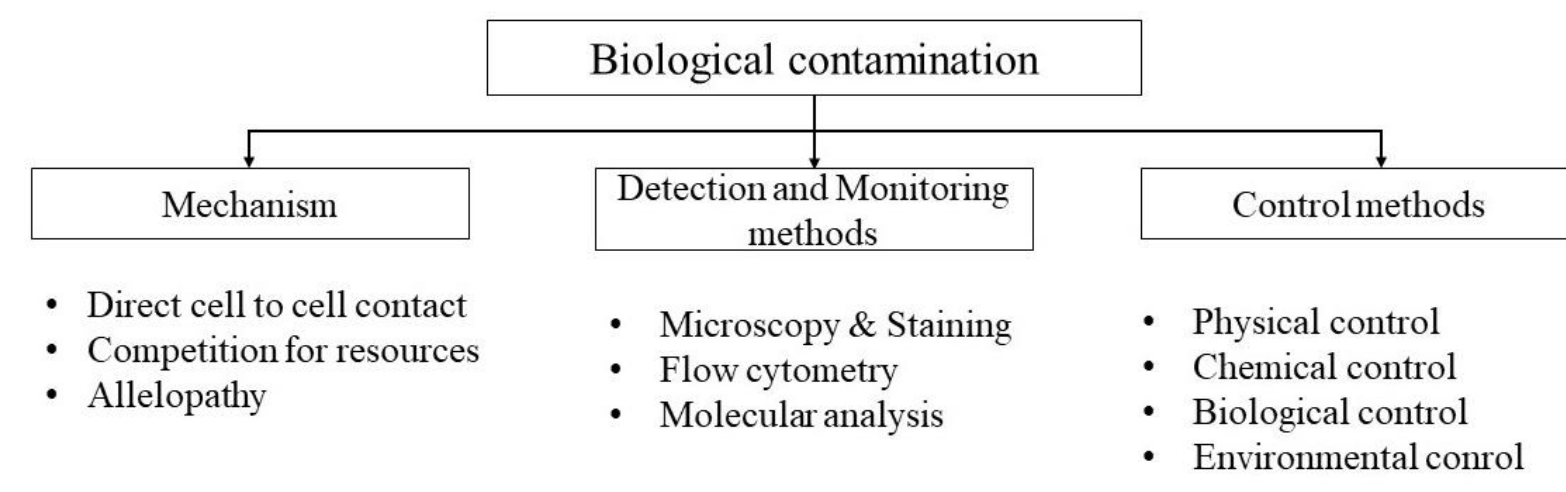

Figure 2. Different mechanisms of contamination, detection and monitoring tools, and control methods of biological contaminants.

\section{Competition for resources}

When available nutrient sources, such as phosphate, nitrogen, potassium, calcium, and magnesium, and dissolved $\mathrm{CO}_{2}$, are less than the potential biological demand, there is generally competition between different algae species. Microalgal species with higher nutrient absorption capacities make better use of available resources and thus dominate competitions. Thus, if any unwanted dominant microalgal species is present as contaminant in the desired microalgae culture; the quality as well as the quantity of the product reduces.

\section{Allelopathy}


Allelopathy is a biological phenomenon in which an organism secretes biochemicals termed allelochemicals that influence the growth, survival, and physiology of other organisms. These allelochemicals have both positive or beneficial and negative or harmful effect on the target organisms. It has been studied that some biological pollutants have negative allelopathy on microalgae culture. Papke et al. [29] reported that Fischerella muscicola, a cyanobacterium secretes an allelochemicals fischerellin A, can stop some microalgae strains from growing. Rengefors and Legrand [30] observed that Pridinium aciculiferum secrets certain substance which interfere in the growth of Rhodomonas lacustris.

Thus, it is very important to emphasize the possibly pathway of biological contamination as the biological contaminants are potential threat in open microalgal pond. As a result, the infectious sources of biological pollutants should be evaluated in order to prevent and limit the level of biological contamination. Generally, the biological contaminants invade into the culture by the input of large volume of water, culture medium, gas exchange between culture and open environment. Their possible routes of contamination are summarised. (A) Contamination through water: At the growing stage, conventional microalgae mass cultivation methods in open pond systems and closed photobioreactors require water ranging from 165 to 2000 gallon/gallon of biodiesel [31]. As a result, mass microalgae and cyanobacteria cultivation require a significant amount of water that cannot be sterilised using the wet heat sterilisation approach (autoclaving method). Despite the fact that the medium can be disinfected by bleaching or filtration prior to mass cultivations of microalgae and cyanobacteria, contamination is still a possibility due to low chlorine concentrations, short treatment times, or insufficient filtering. As a result, the medium will be decontaminated only for the lag phase [9]. (B) Contamination through air: The culture of microalgae and cyanobacteria is exposed to air during bulk cultivation in an open pond. Though this exposure is beneficial for atmospheric $\mathrm{CO}_{2}$ input and dissolved oxygen elimination, it creates more 
opportunities for the biological contaminants to invade the cultivation systems. Even in a closed photobioreactor, continual air or air- $\mathrm{CO}_{2}$ gas mixture supplementation is required for agitation of the bulk volume of microalgae or cyanobacteria cultures. As a result, the more the gas exchange during cultivation, the greater the risk of contamination. (C) Contamination through culture medium: The supplement of nutrients in the culture medium also allows the invading of different biological contaminants. It is very hassle to sterilize large amount of nutrients that are required for mass cultivation in open pond. As a result, early detection and treatment can greatly reduce the likelihood of biological contamination from microalgae and cyanobacterial production. Table 1 . shows different types of biological contaminants predating on various target algae.

Table 1. Various types of biological contaminants and their target algae in open cultivation

\begin{tabular}{|c|c|c|c|}
\hline $\begin{array}{c}\text { Biological } \\
\text { contaminants }\end{array}$ & Target algae & Cultivation system & References \\
\hline $\begin{array}{c}\text { Branchionus sp. } \\
\text { (rotifer) and Amoeba } \\
\text { sp.(amoeba) }\end{array}$ & Arthrospira sp. & Open pond & $\begin{array}{l}\text { Mendez and Uribe } \\
\text { [32] }\end{array}$ \\
\hline Euplotes sp. (ciliate) & Chlorella & Culture tank & Rothbard [33] \\
\hline Copepodans (colpoda) & Chlorella & Open ponds & Loosanoff et al. [34] \\
\hline Colpoda steinii (ciliate) & $\begin{array}{c}\text { Anacystis } \\
\text { nidulans }\end{array}$ & Open raceways pond & Bader et al. [35] \\
\hline $\begin{array}{l}\text { Naegleria sp. and } \\
\text { Cladotricha } s p . \\
\text { (amoebae) }\end{array}$ & Dunaliella salina & Open ponds & Post et al. [36] \\
\hline $\begin{array}{l}\text { Ciliates Unidentified } \\
\text { (ciliate) }\end{array}$ & D. salina & Open ponds & $\begin{array}{c}\text { Moreno and } \\
\text { Canavate [37] }\end{array}$ \\
\hline Monas sp. (flagellate) & Phaeodactylum & $\begin{array}{l}\text { Open tanks for algal } \\
\text { mass cultivation }\end{array}$ & Ansel et al. [38] \\
\hline $\begin{array}{l}\text { Gymnodinium sp. } \\
\text { (flagellate) }\end{array}$ & Porphyridium & $\begin{array}{l}\text { Open raceways for } \\
\text { algal mass } \\
\text { cultivation }\end{array}$ & Ucko et al. [39] \\
\hline $\begin{array}{l}\text { Amphelidium sp. } \\
\text { (flagellate) }\end{array}$ & Scenedesmus & $\begin{array}{l}\text { open ponds for algal } \\
\text { mass cultivation }\end{array}$ & Heussler et al. [40] \\
\hline
\end{tabular}




\begin{tabular}{ccc}
\hline $\begin{array}{c}\text { Vernalophrys sp. } \\
\text { (amoeba) }\end{array}$ & $\begin{array}{c}\text { Scenedesmus } \\
\text { dimorphus }\end{array}$ & $\begin{array}{c}\text { Open raceways for } \\
\text { algal mass } \\
\text { cultivation }\end{array}$ \\
& Gong et al. [41] & \\
\hline
\end{tabular}

\subsection{Various tools for detection and contamination monitoring}

Due to the lack of information about the biology of various possible biological contaminants, there is no reliable methodology being developed till date to address all contaminations. However, detecting biological pollutants early in the mass cultivation of microalgae and cyanobacteria is critical before applying viable culture system mitigation strategies. Generally, the cell concentrations in pure culture are measured using cell count method and biomass is measured by gravimetry or by analysing protein concentrations, chlorophyll content, and total organic carbon. Whereas, in contaminated cultures; microscopic observation as well as several indirect methods are essential to evaluate the microbial population diversity.

\subsubsection{Microscopy and staining methods}

The identification of contamination by microscopic inspection is a straight forward and convenient procedure. This method aids in the observation and evaluation of the growth of various contaminants in an axenic culture. There are various microscopic methods used to observe pollutants nowadays, ranging from the simple optical microscope to confocal, interference, and electron microscopes. The use of dyes to stain biological pollutants is a quick way to identify them. Calcoflour White Stain is a fluorescent dye that is one of the most commonly used staining methods for detecting fungus and other parasites quickly [8]. It binds to the cellulose and chitin of fungal and other organisms' cell walls. The pollutants look green or blue in this staining procedure, whereas the others may see red or orange. Gerphagnon et al. [5] employed a combination of Calcoflour and SYTOX green to determine the degree of 
chytrid contamination. SYTOX Green is a staining agent that is used to identify cells with damaged plasma membranes.

\subsubsection{Flow Cytometric detection}

Flow cytometry is a technique for detecting, identifying, and counting particular cells in the laboratory. Flow cytometry works on the premise of passing cells in a single stream in front of a laser so that they can be identified, counted, and sorted. FlowCAM is a modern detection technology that has gained popularity in recent decades. This method allows for the detection and quantification of phytoplankton species. This method has several advantages over microscopic observation methods, including the ability to analyse mixed populations of algae, cyanobacteria, and bacteria; recognition and identification of grazers in dense culture; and control of biological contaminants in mass culture without loss or damage. Ciliates, copepods, and dinoflagellates can all be detected early with this method [42].

\subsubsection{Method of molecular detection}

Multiple polymerase chain reaction (PCR)-based technologies have been used to detect and identify distinct biological contaminants in algal culture utilising molecular approaches. Invaders of microalgae culture can be identified at levels as low as one in $10^{8}$ cells utilising allele-specific probes and Quantitative PCR (QPCR). In the identification of Tetraselmis striata cells serially diluted in Nannochloropsis salina culture, QPCR has been shown to be $10^{4}$ times more sensitive than flow cytometry [43]. According to Carney et al. [44], microbiome analysis utilising second generation sequencing can reveal both eukaryotic and bacterium contaminants related with culture crashes in Nannochloropsis salina mass cultures. Apart from this, metagenomics, metatranscriptomics, and metaproteomics are other new alternatives to identify biological contaminants in microalgae culture. As a result, molecular techniques are the most likely method for detecting grazers in algal crops early. 


\subsection{Various steps to control biological contaminants}

Biological contamination in microalgae mass production is a major concern nowadays. To control contamination in large-scale cultivation, a range of strategies have been used, including physical control, chemical control, biological control, and environmental control methods.

\subsubsection{Physical control method}

At present, physical method is considered to be the most convenient method for controlling biological contamination. Disinfection of equipment and maintenance of culture media, inoculums are considered under physical control method. Filtration and sonication, ultraviolet sterilization are the common physical methods commonly practiced to intervene the biological contamination. Generally, rotifers and copepods are eliminated in its adult stage having 200 micrometre length using filtration process. Eggs and juvenile rotifers cannot be removed since they are tiny and pass through the meshes. As a result, the filtering must be repeated for 3 to 4 days in order to entirely eradicate the rotifers $[45,9,46]$. This technique, however, is inefficient for pollutants that are similar to or smaller than the microalgae being produced. The technique of sonication or physical disruption of biological pollutants is thought to be more reliable than the physical method. This ultrasound-based sonication has been examined as a viable method of preventing bacterium, phytoplankton, and zooplankton survival. Other physical methods, such as ultraviolet sterilisation and pasteurisation, can be used to keep microalgae cultivation as sterile as possible. Physical approaches are beneficial only in the laboratory and on a pilot scale, but they are useless and expensive in large-scale growth [47]. As a result, physical approaches can be combined with other procedures to achieve the required outcomes.

\subsubsection{Chemical control method}


Chemical control method serves as one of the feasible solutions for intervening biological contaminants of microalgae and cyanobacteria cultivation. Antibiotics, fungicides, pesticides, salts, aldehydes, and peroxides are some of the most commonly employed chemical agents etc. It is most imperative to determine the appropriate chemical agents and their inhibitory concentrations to control the effect of biological contaminants. Park et al [48] found that grazing rotifers were inhibited by sodium hypochlorite doses ranging from 0.45 to $0.6 \mathrm{mg}$ $\mathrm{Cl} / \mathrm{L}$ whereas the microalgae Chlorella kessleri grew unaffected. Cytochalasin is an anti-grazer pesticide targeted towards the inhibition of protozoan [49]. Moreno-Garrido and Canavate [37] indicated that use of quinine sulphate (anti-grazer pesticide) at a concentration of $10 \mathrm{mg} \mathrm{L}^{-1}$ rapidly destroy ciliates in an outdoor cultivation of $D$. salina. Another anti-protozoan medicine that has been used successfully is metronidazole against Amphelidium sp.(zooflagellate) while treating Scenedesmus sp. [40]. Some of the pesticides such as cypermethrin, atrazine, promenton, simetin, and paraquat have successful results in many algae culture. Several researches have been published on the use of chemical agents in open ponds, such as the use of copper to limit B. calyciflorus development in a Chlorella kessleri mass culture [50], hyperchlorite is used to control protozoa in Nannochloropsis cultures. Moreover, Nannochloropsis cultures have been used to maintain as pure culture by the use of glyphosate and ozone [50]. However, such chemicals are expensive to use in large scale algae cultivation. It seems that most of the chemicals could inhibit the growth of microalgae and cyanobacteria and reduce phycocyanin concentration [51]. The usage of such high quantities of chemical reagents has a negative impact on not only the global environment, but also human health and aquatic life. As a result, environmentally friendly biological agents that interfere in biological pollutants without harming microalgae and cyanobacteria cells should be implemented. Table 2. shows a brief description of some chemical agents along with their concentrations used to control biological contamination. 
Table 2. Various types of chemical agents with their concentration used for intervening the biological pollutants.

\begin{tabular}{|c|c|c|c|}
\hline Chemical agents & $\begin{array}{l}\text { Biological pollutants } \\
\text { affected }\end{array}$ & $\begin{array}{l}\text { Concentration of } \\
\text { chemical agents } \\
(\mathrm{ppm})\end{array}$ & References \\
\hline $\begin{array}{l}\text { Unionized } \\
\text { ammonia }\end{array}$ & Amoebae, rotifers & $0.7-9.8$ & Huang et al. [47] \\
\hline Metronidazole & Amoebae & $>200$ & $\begin{array}{c}\text { Moreno-Garrido and } \\
\text { Cañavate [37] }\end{array}$ \\
\hline Quinine sulphate & Ciliate & $12-14$ & \\
\hline Formaldehyde & Ciliate & $10-15$ & \\
\hline $\begin{array}{l}\text { Hydrogen } \\
\text { peroxide }\end{array}$ & Ciliate & $150-200$ & \\
\hline Trichlorphon & Rotifers & $274-318$ & Huang et al. $[46,47,52]$ \\
\hline Pyrethroids & Rotifers & $0.30-1.28$ & \\
\hline Celangulin & Rotifers & 0.175 & \\
\hline Toosendanin & Rotifers & 0.002132 & \\
\hline Azadirachtin & Rotifer & 18.38 & \\
\hline $\begin{array}{l}\text { Ammonium } \\
\text { bicarbonate }\end{array}$ & Rotifers & $100-150$ & \\
\hline Rotenone & Rotifers & $0.070-0.1380$ & Van Ginkel et al. [53] \\
\hline Buprofezin & Rotifer & $240-263$ & Wang et al. [9] \\
\hline Ampicillin & Bacteria/fungi & 500 & Kan and Pan [17] \\
\hline Cefotaxime & Bacteria/fungi & 100 & \\
\hline Carbendazim & Bacteria/fungi & 40 & \\
\hline
\end{tabular}

\subsubsection{Biological control method}

The use of biological control measures is a relatively new approach that overcomes the limitations of traditional chemical treatments by reducing toxicity to microalgae and cyanobacteria cells. In comparison to conventional chemical agents, pesticides derived from plants may be a better choice for managing biological pollutants in microalgae and cyanobacteria mass cultures. Celangulin, matrine, and toosendanin are all considered viable biopesticides for rotifer control in microalgae mass cultivation [47]. These insecticides attack the animals' digestive system, causing death owing to cellular damage in the midgut. Zhang et 
al. [54] found the elevation in photosynthetic performance of Nannochloropsis cells while using the combination of celangulin and toosendanin at 1:9 ratio, which could be due to the elimination of Brachionus plicatilis (rotifer) breeding. As a result, plant-derived insecticides have the potential and feasibility to intervene in biological contaminations in microalgae and cyanobacteria mass cultures.

\subsubsection{Environmental control method}

Many strains of microalgae and cyanobacteria are resistant to harsh environmental culture conditions like $\mathrm{pH}$, temperature, and light intensity. As a result, altering these environmental factors to a range where only microalgae or cyanobacteria strains may live in the absence of biological pollutants might be considered an ideal strategy for biological contaminants eradication. In order to eradicate biological contaminants, it has been demonstrated that Spirulina grows well in extreme high $\mathrm{pH}$ and Dunaliella grows well in severe high salinity circumstances [55]. Touloupakis et al. [56] found that Synechocystis strain (cyanobacteria) which is alkaline tolerant grow well at extreme $\mathrm{pH} 11$ than Poterioochromonas strain (golden algae). Because it is particularly sensitive to alkaline stress at $\mathrm{pH} 11$, the Poterioochromonas strain performed poorly or was even destroyed. In addition, adding carbonate to the culture raises the $\mathrm{pH}$, removing biological pollutants from the desired microalgae or cyanobacteria mass culture. Furthermore, light shock (a fast rise in light intensity to $30,000 \mathrm{Lux}$ ), salinity shock (over $15 \% \mathrm{NaCl}$ ), and temperature shock could all influence the pollutants' capacity to survive in a microalgae mass culture.

\section{Research challenges and further approaches}

It is evident that there is no reliable and permanent methodology to prevent and control the biological pollutant in microalgae mass culture till date. Despite the existence of several control mechanisms like as physical and chemical approaches, they have been described as 
costly, ineffectual, and environmentally dangerous in the large-scale production of microalgae biomass. To avoid biological contamination in mass culture, it is critical to research the potential and robust procedures that will be specific for each microalgae culture, as well as the discovery of low-cost, environmentally friendly, and non-toxic substances. Although, bulk amount of microalgae biomass production is done in open systems, it faces problems with biological contamination. Some of the controlling steps could be implemented such as application followed by identification and testing of appropriate biological agents (bacteria and viruses) to control weed algal species. In this prospect, refrain from contamination, and management of contaminant grazers are an important step to be considered before mass cultivation.

\section{Conclusion}

The microalgae biomass is gaining popularity due to its various potential applications. Several microbes can contaminate large-scale production of microalgae biomass in an open growing method. As a result, there is the loss of entire culture due to the myriad types of biological contaminants and their possible interactions in culture. Therefore, reasonable cultivation technology, contaminants detection technologies along with reliable and sustainable pollutant control methods should be established to promote industrialization of microalgae cultivation in future.

\section{Acknowledgement}

This work was supported by Algaline Pvt. Ltd. and is gratefully acknowledged.

\section{Author's contribution}

Bidhu Bhusan Makut was in charge of the review's conceptualization and design. Saubhagya Manjari Samantaray was primarily responsible for data collection. The review article was written by Bidhu Bhusan Makut and Saubhagya Manjari Samantaray. 


\section{Potential for conflict of interest}

There are no disputes', informed permission is given, and human and animal rights are respected.

\section{References}

1. Rizwan, M.; Mujtaba, G.; Memon, S.A.; Lee, K.; Rashid, N. Exploring the potential of microalgae for new biotechnology applications and beyond: a review. Renew. Sustain. Energy. Rev. 2018, 92:394-404.

2. Wang, L.; Yuan, D.; Li, Y.; Ma. M.; Hu, Q.; Gong, Y. Contaminating microzooplankton in outdoor microalgal mass culture systems: An ecological viewpoint. Algal. Res. 2016, 20:258-266.

3. Day, J.G.; Gong, Y.; Hu, Q. Micro zooplanktonic grazers-A potentially devastating threat to the commercial success of microalgal mass culture. Algal. Res. 2017, 27:356365.

4. Zhu, Z.; Jiang, J.; Fa, Y. Overcoming the Biological Contamination in Microalgae and Cyanobacteria Mass Cultivations for Photosynthetic Biofuel Production. Molecules 2020, 25:5220.

5. Gerphagnon, M.; Latour, D.; Colombet, J.; Sime-Ngando, T. Fungal parasitism: life cycle, dynamics and impact on cyanobacterial blooms. PloS One. 2013, 8:60894.

6. Sieracki, C.K.; Sieracki, M.E.; Yentsch, C.S. An imaging-in-flow system for automated analysis of marine microplankton. Mar. Ecol. Prog. Ser. 1998, 168:285-296. 
7. Havlik, I.; Reardon, K.F.; Ünal, M.; Lindner, P.; Prediger, A.; Babitzky, A.; Scheper, T. Monitoring of microalgal cultivations with on-line, flow-through microscopy. Algal. Res. 2013, 2:253-257.

8. Carney, L.T.; Lane T.W. Parasites in algae mass culture. Front. Microbiol. 2014, 5:278.

9. Wang, H.; Zhang, W.; Chen, L.; Wang, J.; Liu, T. The contamination and control of biological pollutants in mass cultivation of microalgae. Bioresour. Technol. 2013, 128:745-750.

10. Montemezzani, V.; Duggan, I.C.; Hogg, I.D.; Craggs, R.J. A review of potential methods for zooplankton control in wastewater treatment High-Rate Algal Ponds and algal production raceways. Algal. Res. 2015, 11:211-226.

11. Brusca, R.C.; Brusca, G.J. Invertebrates. 2nd Edition. Sinauer Associates, Sunderland, Massachusetts, 2003, pp-936.

12. Brandão, S.N.; Angel, M.V.; Karanovic, I.; Parker, A.; Perrier, V.; Yasuhara M. World Ostracoda Database http://www.marinespecies.org/ostracoda. 2016, Accessed 02 April 2018.

13. Li, J.L.; Zhang, X.P.; Wu, S.Z.; Zheng, W.F. Effects of nutrient concentrations on the growth and accumulation of exopolysaccharides of spaceflight Dunaliella salina. J. Wuhan. Bot. Res. 2006, 24:149-153.

14. Park, S. The selective use of chlorine to inhibit algal predators and avoid pond crashes for the algae-biodiesel industry (Doctoral dissertation, Georgia Institute of Technology). 2014.

15. Hoffman, Y.; Aflalo, C.; Zarka, A.; Gutman, J.; James, T.Y.; Boussiba, S. Isolation and 
characterization of a novel chytrid species (phylum Blastocladiomycota), parasitic on the green alga Haematococcus. Mycol. Res. 2008, 112:70-81.

16. Fott, B. Phlyctidium scenedesmi spec. nova, a new chytrid destroying mass cultures of algae. Z. Allg. Mikrobiol. 1967, 7:97-102.

17. Kan, Y.; Pan, J. A one-shot solution to bacterial and fungal contamination in the green alga chlamydomonas reinhardtii culture by using an antibiotic cocktail 1. J. Phycol. 2010, 46:1356-1358.

18. Letcher, P.M.; Lopez, S.; Schmieder, R.; Lee, P.A.; Behnke, C.; Powell, M.J.; McBride, R.C. Characterization of Amoeboaphelidium protococcarum, an algal parasite new to the cryptomycota isolated from an outdoor algal pond used for the production of biofuel. PloS One. 2013, 8:56232.

19. Amin, S. A.; Parker, M. S.; Armbrust, E. V. Interactions between diatoms and bacteria. Microbiol. Mol Biol. Rev. 2012, 76:667.

20. Banin, E.; Israely, T.; Kushmaro, A.; Loya, Y.; Orr, E.; Rosenberg, E. Penetration of the coral-bleaching bacterium Vibrio shiloi into Oculina patagonica. Appl. Environ. Microbiol. 2000, 66: 3031-3036.

21. Nakashima, T.; Miyazaki, Y.; Matsuyama, Y.; Muraoka, W.; Yamaguchi, K.; Oda, T. Producing mechanism of an algicidal compound against red tide phytoplankton in a marine bacterium $\gamma$-proteobacterium. Appl. Microbiol. Biotechnol. 2006, 73:684-690.

22. Rowe, J.M.; Dunigan, D.D.; Blanc, G.; Gurnon, J.R.; Xia, Y.; Van Etten, J.L. Evaluation of higher plant virus resistance genes in the green alga, Chlorella variabilis 
NC64A, during the early phase of infection with Paramecium bursaria chlorella virus1. Virology. 2013, 442:101-113.

23. Safferman, R.S.; Morris, M.E. Algal virus: isolation. Science. 1963, 140:679-680.

Sanchez, C.S.; Durandchastel, H. Utilization of Spirulina Algae for Industrial Photosynthesis. In. J. phycol. 1977, (Vol. 13, pp. 60-60) 810 east 10th st, lawrence, ks 66044: phycological soc. amer. inc.

24. Gibbs, A.; Skotnicki, A.H.; Gardiner, J.E.; Walker, E.S.; Hollings, M. A tobamovirus of a green alga. Virol. J. 1975, 64:571-574.

25. Nagasaki, K.; Tarutani, K.; Yamaguchi, M. Growth characteristics of Heterosigma akashiwo virus and its possible use as a microbiological agent for red tide control. Appl. Environ. Microbiol. 1999, 65:898-902.

26. Ma, A.T.; Daniels, E.F.; Gulizia, N.; Brahamsha, B. Isolation of diverse amoebae grazers of freshwater cyanobacteria for the development of model systems to study predator-prey interactions. Algal. Res. 2016, 13:85-93.

27. Berney, C.; Romac, S.; Mahé, F.; Santini, S.; Siano, R.; Bass, D. Vampires in the oceans: predatory cercozoan amoebae in marine habitats. The ISME journal. 2013, 7:2387-2399.

28. Yamasaki, Y.; Nagasoe, S.; Matsubara, T.; Shikata, T.; Shimasaki, Y.; Oshima, Y.; Honjo, T. Growth inhibition and formation of morphologically abnormal cells of Akashiwo sanguinea (Hirasaka) G. Hansen et Moestrup by cell contact with Cochlodinium polykrikoides Margalef. Mar. Biol. 2007, 152:157-163. 
29. Papke, U.; Gross, E.M.; Francke, W. Isolation, identification and determination of the absolute configuration of fischerellin $B$. A new algicide from the freshwater cyanobacterium Fischerella muscicola. Tetrahedron. Lett. 1997, 38:379-382.

30. Rengefors, K.; Legrand, C. Toxicity in Peridinium aciculiferum-an adaptive strategy to outcompete other winter phytoplankton? Limnol. Oceanogr. 2001, 46:1990-1997.

31. Tu, Q.; Lu, M.; Thiansathit, W.; Keener, T.C. Review of water consumption and water conservation technologies in the algal biofuel process. Water Environ. Res. 2016, $88: 21-28$.

32. Méndez, C.; Uribe, E. Control the Branchionus sp. y Amoeba sp. en cultivos de Arthrospira sp. Lat Am J. Aquat. Res. 2012, 40: 553-561.

33. Rothbard, S. Control of Euplotes sp. by formalin in growth tanks of Chlorella sp. used as growth medium for the rotifer Brachionus plicatilis which serves as feed for hatchlings. Bamidgeh. 1975, 27:100-109.

34. Loosanoff, V.L.; Hanks, J.E.; Ganaros, A.E. Control of certain forms of zooplankton in mass algal cultures. Science. 1957, 125:1092-1093.

35. Bader, F. G.; Tsuchiya, H. M.; Fredrickson, A. G. Grazing of ciliates on blue-green algae: Effects of ciliate encystment and related phenomena. Biotechnol. Bioeng. 1976, 18: $311-332$.

36. Post, F.J.; Borowitzka, L.J.; Borowitzka, M.A.; Mackay, B.; Moulton, T. The protozoa of a Western Australian hypersaline lagoon. Hydrobiologia. 1983, 105:95-113. 
37. Moreno-Garrido, I.; Canavate, J.P. Assessing chemical compounds for controlling predator ciliates in outdoor mass cultures of the green algae Dunaliella salina. Aquac. Eng. 2001, 24:107-114.

38. Ansell, A. D.; Raymont, J. E. G.; Lander, K. F.; Crowley, E.; Shackley, P. Studies on the mass culture of Phaeodactylum. II. The growth of Phaeodactylum and other species in outdoor tanks. Limnol. Oceanogr. 1963, 8:184-206.

39. Ucko, M.; Cohen, E.; Gordin, H.; Arad, S. Relationship between the unicellular red alga Porphyridium sp. and its predator, the dinoflagellate Gymnodinium sp. Appl. Environ. Microbiol. 1989, 55:2990-2994.

40. Heussler, P.; Castillo, S.; Merino, F.M. Parasite problems in the outdoor cultivation of Scenedesmus. Arch. Hydrobiol. Beih. Erg. Limnol. 1978, 11:223-227.

41. Gong, Y.; Patterson, D.J.; Li, Y.; Hu, Z.; Sommerfeld, M.; Chen, Y.; Hu, Q. Vernalophrys algivore gen. nov., sp. nov. (Rhizaria: Cercozoa: Vampyrellida), a new algal predator isolated from outdoor mass culture of Scenedesmus dimorphus. Appl. Environ. Microbiol. 2015, 81: 3900-3913.

42. Haraguchi, L.; Jakobsen, H.H.; Lundholm, N.; Carstensen, J. Phytoplankton community dynamic: a driver for ciliate trophic strategies. Front. Mar. Sci. 2018, 5:272.

43. Fulbright, S.P.; Dean, M.K.; Wardle, G.; Lammers, P.J.; Chisholm, S. Molecular diagnostics for monitoring contaminants in algal cultivation. Algal. Res. 2014, 4:41-51.

44. Carney, L.T.; Wilkenfeld, J.S.; Lane, P.D.; Solberg, O.D.; Fuqua, Z.B.; Cornelius, N.G.; Lane, T.W. Pond crash forensics: presumptive identification of pond crash agents by next generation sequencing in replicate raceway mass cultures of Nannochloropsis salina. Algal. Res. 2016,17: 341-347. 
45. González-López, C.V.; Cerón-García, M.C.; Fernández-Sevilla, J.M.; GonzálezCéspedes, A.M.; Camacho-Rodríguez, J.; Molina-Grima, E. Medium recycling for Nannochloropsis gaditana cultures for aquaculture. Bioresour. Technol. 2013, 129:430-438.

46. Huang, Y.; Liu, J.; Li, L.; Pang, T.; Zhang, L. Efficacy of binary combinations of botanical pesticides for rotifer elimination in microalgal cultivation. Bioresour. Technol. 2014b, 154:67-73.

47. Huang, Y.; Li, L.; Liu, J.; Lin, W. Botanical pesticides as potential rotifer-control agents in microalgal mass culture. Algal. Res. 2014a, 4:62-69.

48. Park, S.; Van Ginkel, S.W.; Pradeep, P.; Igou, T.; Yi, C.; Snell, T.; Chen, Y. The Selective Use of Hypochlorite to Prevent Pond Crashes for Algae-Biofuel Production. Water Environ. Res. 2016, 88:70-78.

49. Leakey, R.J.; Wilks, S.A.; Murray, A.W. Can cytochalasin B be used as an inhibitor of feeding in grazing experiments on ciliates? Eur. J. Protistol. 1994, 30:309-315.

50. Pradeep, V.; Van Ginkel, S.W.; Park, S.; Igou, T.; Yi, C.; Fu, H.; Chen, Y. Use of copper to selectively inhibit Brachionus calyciflorus (Predator) growth in Chlorella kessleri (Prey) mass cultures for algae biodiesel production. Int. J. Mol. Sci. 2015, 16:20674-20684.

51. Chen, H.; Jiang, J.G. Toxic effects of chemical pesticides (trichlorfon and dimehypo) on Dunaliella salina. Chemosphere 2011, 84:664-670.

52. Huang, Y.; Liu, J.; Wang, H.; Gao, Z. Treatment potential of a synergistic botanical pesticide combination for rotifer extermination during outdoor mass cultivation of Spirulina platensis. Algal. Res. 2014c, 6:139-144. 
53. Van Ginkel, S.W.; Bidwell, M.; Igou, T.; Gijon-Felix, R.; Salvi, E.J.N.R.; De Oliveira, S.H.R.; Chen, Y. The prevention of saltwater algal pond contamination using the electron transport chain disruptor, rotenone. Algal. Res. 2016, 18:209-212.

54. Zhang, L.T.; Xu, R.; Liu, J.G. Efficacy of botanical pesticide for rotifer extermination during the cultivation of Nannochloropsis oculata probed by chlorophyll a fluorescence transient. Photosynthetica. 2020, 58:341-347.

55. Borowitzka, L. J.; Borowitzka, M. A. Commercial production of $\beta$-carotene by Dunaliella salina in open ponds. Bull. Mar. Sci. 1990, 47:244-252.

56. Touloupakis, E.; Cicchi, B.; Benavides, A.M.S.; Torzillo, G. Effect of high pH on growth of Synechocystis sp. PCC 6803 cultures and their contamination by golden algae (Poterioochromonas sp.). Appl. Microbiol. Biotechnol. 2016, 100:1333-1341. 